\title{
O CAVALEIRO NAS CANTIGAS DE SANTA MARIA
}

\author{
Eduardo Cursino de Faria Chagas \\ Universidade Federal de Minas Gerais
}

\begin{abstract}
This paper aims to expose the theme of chivalry in the Cantigas de Santa Maria, compiled at the court of King Alfonso $\mathrm{X}$ the Wise (1221-1284). The purpose of this study is to approach the following topics: the spiritual and amorous vassalage service of the knight towards the lady and values of chastity, fidelity and faith, present in the selected corpus (eight songs), which deals with the aforementioned issues, examining not only the symbolism of the chivalry, but also the devotion to the Virgin, and how she helps the knight's religiosity and obedience, who honors the ritual accolade's oath and the weapons' watch, rites which are celebrated in the Church.
\end{abstract}

KEYWORDS: Cantigas de Santa Maria; Alfonso X; chivalry; trovadorism; chivalric romance.

\section{Introdução}

e s Cantigas de Santa Maria (CSM) produzidas na corte de Afonso X (1221-1284) constituem um grupo de composições de caráter narrativo (cantigas de milagre) e de caráter lírico (cantigas de louvor), distribuídas de dez em dez, isto é, a cada grupo de nove cantigas de milagre segue-se uma cantiga de louvor, contendo 427 poemas acompanhados de belissímas iluminuras e notações musicais. As CSM chegaram até a atualidade

$\overline{\star c h a e d f a b e l @ g m a i l . c o m}$ 
em quatro códices diferentes, ${ }^{1}$ escritos em galego-português, a língua privilegiada da lírica medieval ibérica. Os quatro códices - identificados pelas siglas To, E, T, e F — são precedidos por um prólogo que ilustra a intenção de exaltar a figura de Maria com todo o espírito e a arte que um trovador podia oferecer. O próprio Afonso X apresenta-se em muitas cantigas como aquele que dedicou as suas capacidades artísticas não a uma mulher terrena, mas sim à dama celeste.

Dentre as iluminuras que enriquecem o corpus das CSM destaca-se a do Prólogo B, em que podemos ver o rei mecenas ajoelhado perante a Virgem, revelando-se a presença de poética e ideologia profanas, graças às quais a Virgem acaba por se tornar quase indistinta da mulher cantada pelos trovadores. Essa atitude servil diante de Maria possui semelhanças com o comportamento do trovador perante sua dama, como presente em poemas produzidos na região do Midi francês, escritos em língua d'oc. É importante considerar que esse serviço amoroso de submissão absoluta à dama, ainda de traços essencialmente profanos, por vezes sublimados, havia se difundido rapidamente pela Europa, dando origem ao grande tema da inspiração lírica medieval: o amor cortês. É de se notar que esses poemas de caráter eminentemente laico, em cujas bases o próprio conceito de amor cortês legitimava uma relação adúltera entre a dama e seu amante, acabavam sendo sublimados pela moralização da poesia religiosa, muito bem exemplificada nas CSM, nas quais o adultério e a coita amorosa eram males que deveriam ser extirpados. Por meio da intercessão de Maria, cavaleiros apaixonados tinham os seus corações livres da angústia amorosa e o casamento tornava-se exclusivamente um motivo de felicidade. Em suma, nas CSM, o sofrimento amoroso, a lascívia e o adultério - elementos caros à poética cortês - eram reduzidos a um significado maniqueísta, associado ao pecado.

Os motivos e processos que resultaram no cerceamento e na transformação de temas de conteúdo laico em seus correspondentes de natureza cristã, presentes na poesia religiosa do rei Afonso X, são o objetivo desse artigo. Em nossa análise, verificamos que aproximadamente quarenta e três cantigas têm como personagem o cavaleiro; entretanto, fizemos um recorte e apenas oito cantigas constituirão o nosso corpus. Nessas cantigas, o cavaleiro se manifesta idealizado por suas atitudes e por características típicas dos romances corteses e do código da cavalaria. Nosso estudo se

${ }^{1}$ Códice To: Toledo; Códice E: Escurialense; Códice T: Códice Rico; Códice F: Códice Florentino. 
baseia no livro de conduta da cavalaria ${ }^{2}$ de Ramon Llull (1232-1315) e na obra de Afonso X, Las Siete Partidas, que regulamentam o código de conduta da classe guerreira, baseado nos moldes corteses e cristãos da Idade Média.

Constatamos um tema recorrente na maior parte das cantigas selecionadas: o repúdio ao amor carnal e ao adultério, típicos dos romances corteses e fonte da maioria das desventuras que o cavaleiro enfrenta. A concupiscência era o caminho para o inferno e, de acordo com os dogmas da Igreja, era através da castidade que a salvação poderia ser atingida. As CSM possuem em comum a mensagem moralizante acerca da perdição da alma para aquele que se envolve com os desejos da carne e, em contrapartida, evidenciam também o deleite da alma que segue os preceitos morais do exemplo da Virgem: a castidade.

\section{O Amor Cortês nas Cantigas de Santa Maria}

No século XII, quase um século antes da criação das CSM, o trovadorismo teve sua gênese em terras provençais. Entre as motivações que desencadearam esse tipo de poesia ressaltam-se as mudanças sociais, que favoreceram a crescente valorização da mulher. ${ }^{3}$ Face à ascensão feminina e ao desenvolvimento de uma literatura cortês de fortes traços eróticos, ocorria uma acirrada oposição eclesiástica, na qual a Igreja, desejosa de extirpar o conteúdo malicioso dessas produções artísticas, passava a adaptar seus temas amorosos em narrativas piedosas surgidas a partir de meados do século XI. ${ }^{4}$ A partir dessa época, Maria recebeu o título de "rainha celeste", e, desde então, a figura da dama da corte foi substituída pela da Virgem, e as ordens monásticas passaram a ser réplicas das ordens cavaleirescas. Além dos motivos políticos e sociais, a poética trovadoresca foi buscar no Cristianismo o gosto pela análise interior e a veemência da sua emoção. A convivência dos dois polos, profano e religioso, favoreceu um aspecto contraditório do amor cortês e de sua poética: houve, por um lado, o delírio ascético e a consagração do individualismo, e, por outro, a concupiscência e a mesura. A dama foi sublimada a ponto de parecer por vezes idealizada, como no poema de Guilherme IX (1071-1026), Farai un vers de dreit nien:

\footnotetext{
${ }^{2}$ Libro de la Orden de Caballeria.

${ }^{3}$ A vassalagem amorosa do trovador e dos cavaleiros não correspondia à realidade social, pois a dama adorada nos poemas não era a mesma do cotidiano medieval, revelando mais um fingimento poético.

${ }^{4}$ Cf. Le Goff, 1967, p. 4.
} 
Tenho amiga, não sei quem é, pois nunca a vi, por minha fé; para mim, santa não é, nem ré, o que é igual: normando ou francês nem ao pé do meu quintal. ${ }^{5}$

Em contrapartida, é vista como fonte de preocupação e prazer, instrumento de tirania e de encanto, como bem descrito nesta outra poesia de Guilherme IX, Farai chansoneta nueva:

Mais branca sois que marfim, outra alguma adoro assim. Se em breve não tenho o sim da boa dona que eu amo, por S. Gregório, é meu fim sem seu beijo em cama ou sob ramo. ${ }^{6}$

Nas CSM os ideais do amor cortês mesclam-se aos do Cristianismo, promovendo um surpreendente resultado, como, por exemplo, na cantiga 10, Rosa das rosas, ${ }^{7}$ em que se louva a beleza e a caridade protetora da Virgem. Nessa, e em outras cantigas pertencentes ao corpus afonsino, Maria é digna de todo o amor e louvor e configura-se como superior à inconstante e implacável dame sans merci do amor cortês: "[E]m nome dela desejo divulgar os milagres que realizou, e imediatamente quero deixar de trovar por outra senhora, e me ocuparei em recuperar para a Virgem o que às mulheres fui oferecer". 8

Nas CSM, o poeta se declara entendedor da Virgem, isto é, seu namorado, conceito usado na terminologia cortês, em que se distinguiam graus de relacionamento amoroso: o fenhedor ou aspirante; o precador, o que ousa pedir; o entendedor ou enamorado, e por fim, o drutz ou amante. "E por isso seu namorado serei enquanto eu viver e também a louvarei. Além disso, as muitas bondades que fez divulgarei além dos inúmeros e notáveis milagres, disso tenho prazer".

Na parte lírica da produção afonsina, as cantigas de louvor revelam o trovador diante da Virgem enaltecendo-lhe, além da beleza, ${ }^{10}$ as virtudes

\footnotetext{
${ }^{5}$ Guilherme IX (trad. Arnaldo Saraiva - 2009, p. 53).

${ }^{6}$ Guilherme IX (trad. Arnaldo Saraiva - 2009, p. 77).

${ }^{7}$ Cf. Mettmann, 1969, p. 33 (vol. 1).

${ }^{8}$ [...] ca per el quer'eu mostrar dos miragres que ela fez; e ar querrei-me leixar de trobar des $i$ por outra dona, e cuid'a cobrar per esta quant'enas outras perdi (Mettmann, 1969, p. 2-3 - vol. 1, trad. nossa).

${ }^{9}$ E poren seu entendedor serei enquant' eu viva, e a loarei e de muitos bẽes que faz direi e miragres grandes, ond' ei sabor (Mettmann, 1969, p. 82-83 - vol. 2, trad. nossa).

${ }^{10}$ A beleza física está entre as qualidades pertencentes ao tópos do pretz, ou seja, o renome social.
} 
de seu espírito e todas as qualidades pertencentes ao amor cortês: mesura, valor e honra. A Virgem é aquela que em si possui todas as virtudes, ${ }^{11}$ além de ser dotada de uma beleza sem par, ${ }^{12}$ aos olhos do poeta; esses elogios encontram um paralelismo perfeito com os dispensados pelo trovador à dama da corte; entretanto, em algumas poesias, o poeta lamenta o prejuízo moral devido ao procedimento da senhora, fato não observado na relação entre o fiel e Santa Maria nas CSM n ${ }^{\circ} 63$ e n¹6 abordadas mais adiante.

No Prólogo B das CSM, Afonso X registra bem o sentimento de poder confiar mais na mãe de Jesus do que nas outras damas. Essa fé depositada na Virgem ocorre em todo o corpus das CSM, "[p]ois tão grande é o amor desta Senhora, que quem o tem sempre mais há de ter, e após ganhá-lo, não lhe faltará nada, a não ser que, por desamor, queira deixar o bem e só o mal fazer". ${ }^{13}$ Afonso X recebia graças da Virgem, principalmente a cura de enfermidades - o que pode ser constatado em várias cantigas — como sinal do reconhecimento, por parte de Maria, da dedicação do soberano e dos louvores a ela prestados. Há, entre as CSM, um conjunto de três cantigas que abordam as doenças enfrentadas pelo monarca: as cantigas 209, 235, 279 relatam como a Virgem o fez recuperar a sua saúde, mesmo depois de ele ser tido como desenganado. Na segunda e terceira estrofes da cantiga 209, Afonso X evidenciou toda a motivação dos seus louvores à Virgem, depois de ter sido curado por ela. ${ }^{14}$ Aqui podemos perceber os serviços da dama celestial para com o seu cavaleiro leal, nos moldes do amor cortês, sempre generosa com quem a servia, além de retratar um cavaleiro atento aos preceitos cristãos da ordem da cavalaria.

\section{Santa Maria: alento para a vida no serviço da cavalaria}

A castidade de Maria inspirou a ideia e os discursos acerca da virgindade, porém a obediência à ascese cristã e o controle dos impulsos do corpo eram tarefas árduas para os fiéis, e principalmente para os cavaleiros, sendo, portanto, o motivo da queda para o Inferno inevitável. Dessa forma, para que a falta de esperança não levasse os fiéis à entrega completa

\footnotetext{
${ }^{11}$ Cf. Mettmann, 1969, p. 97-98 (vol. 3).

${ }^{12}$ Cf. Mettmann, 1969, p. 49-51 (vol. 3).

${ }^{13}$ Ca o amor desta Sennor é tal, que queno á sempre per i mais val; e poi-lo gaannad' á, non lle fal, senon se é per sa grand' ocajon, querendo leixar ben e fazer mal, ca per esto o perd' $e$ per al non (Mettmann, 1969, p. 2-3 - vol. 1, trad. nossa).

${ }^{14}$ Cf. Mettmann, 1969, p. 274-275 (vol. 2).
} 
ao pecado, um esquema tripartido foi elaborado. Segundo o historiador Jacques Le Goff, ${ }^{15}$ esse esquema possibilitava três graus de perfeição no caminho da castidade, numa escala descendente: a virgindade, a viuvez e, por fim, o casamento. Sendo assim, a vida casta de Santa Maria foi utilizada como modelo a ser seguido, para os que optassem pela virgindade. Ela tornou-se modelo para todo o corpo social, em especial para a ordem da cavalaria.

O conjunto das CSM representa um corpus dos mais importantes da literatura medieval, pois a partir dele podemos analisar alguns aspectos da vida popular, do clero e da corte, além das crenças de uma sociedade marcada pela diversidade cultural, como as discussões acerca da virgindade de Maria, exemplificadas na cantiga 306: Como Santa Maria fez converter un erege en Roma que dizia que Santa Maria non podia seer virgen e aver fillo. ${ }^{16} \mathrm{Nessa}$ cantiga, como o título indica, ocorre uma discussão acerca da pureza de Maria, travada entre um herege e um grupo de fiéis. Assim que ocorre o milagre, confirmando o engano do incrédulo, este prontamente se arrepende e pede perdão.

Além da castidade como tópos do romance cortês — como podemos observar no exemplo de Galaaz, ${ }^{17}$ cavaleiro casto e fiel ao Cristianismo o tema da concupiscência também foi abordado nas CSM. Os poemas selecionados permitem observar uma ampla gama de situações, nas quais a beleza física tanto do cavaleiro quanto da dama é destacada como sendo fonte da coita amorosa e dos desejos.

Como afirmou Paul Zumthor, ${ }^{18} \mathrm{em}$ A letra e a voz, os textos medievais, na maioria das vezes, eram compostos para serem cantados em público, como as próprias CSM. Essa é outra característica da produção afonsina, cuja resposta encontra-se no esquema do zejel, predominante nas narrativas de milagres. A adaptação para o canto do abundante material narrativo coletado desencadeou uma série de problemas difíceis de serem resolvidos, conforme citam Tavani e Lanciani. ${ }^{19}$ Entretanto, eles foram ultrapassados, graças a operações de corte e uso livre do enjambement de estrofe a estrofe, além do já mencionado método zejelesco. Dessa forma, o seu caráter didático, com os seus aspectos morais e teológicos, era narrado de forma simples e breve para todas as classes sociais, em especial, para os cavaleiros e damas da corte.

\footnotetext{
${ }^{15}$ Cf. Le Goff; Schmitt, 2006.

${ }^{16}$ Cf. Mettmann, 1969, p. 136-137 (vol. 3).

${ }^{17}$ Cf. Magne, 1944.

${ }^{18}$ Cf. Zumthor, 1983, p. 35-54.

${ }^{19}$ Cf. Lanciani; Tavani, 1993 , p. 142 e p. 147.
} 
Nesse contexto apresentado, o amor cortês desempenhou um importante papel nas CSM, no tocante ao didatismo religioso e na condenação dos chamados vícios que muito permeavam a literatura dos romances corteses: o amor ideal é destinado aos serviços de vassalagem à Virgem.

$\mathrm{Na}$ poesia afonsina, o jogo do amor cortês - coita amorosa e a felicidade amorosa encontrada apenas fora do casamento, ou seja, no adultério - é agora tratado como influência do demônio; mantendose, desse amor, apenas o serviço de vassalagem espiritual prestado exclusivamente à sua Senhor, cuja beleza só é igualada ao virtuosismo moral. Já na cantiga 16, fez-se necessária a intervenção da Virgem para livrar um cavaleiro da coita amorosa, cujo sofrimento é sanado diante da beleza de Maria; ao final da cantiga é nítido o enaltecimento da Virgem em detrimento da dama. Em seu refrão canta-se: Quen dona fremosa e boa quiser amar, am' a Groriosa e non poderá errar, portanto, o caminho adequado é o amor divino da Virgem, impossível de ser vivido no mundo carnal, como podemos ver no final da cantiga, já que o cavaleiro é conduzido ao Paraíso depois de um ano. A Virgem é representada de maneira tão inacessível quanto a dama da corte, pois a promessa de uma vida bem-aventurada em sua companhia apenas poderia se concretizar no Paraíso, ao contrário do que ocorre na lírica cortês, a qual buscava a consolidação do amor carnal, por vezes adúltero e preso ao mundo físico. Do código do amor cortês decorrem vários sentimentos, como a perturbação dos sentidos e a loucura, que podiam acometer o cavaleiro dos romances corteses, podendo às vezes levá-lo à morte; menciona-se ainda o enaltecimento da concupiscência do cavaleiro, porém esses sentimentos, típicos de tal gênero, são postos no campo do menosprezo nas CSM.

De acordo com o código do amor cortês, a concretização dos prazeres carnais no adultério era a única expressão possível do verdadeiro amor, confirmado pelas palavras de Marie de Champagne: [... digo que o amor não se pode desenvolver entre dois casados; porque os amantes dão-se reciprocamente tudo, ao passo que os casados se obrigam à obediência. ${ }^{20}$ Segundo Denis de Rougemont, ${ }^{21}$ uma das bases do amor cortês é justificar o adultério, já que o casamento havia se tornado para a nobreza um meio de anexação de terras oferecidas em dote, e quando a transação fracassava, repudiava-se a mulher. A esses abusos o amor cortês opõe uma fidelidade independente das leis do matrimônio, fundada exclusivamente no amor. Este é um sentimento cheio de sofrimento e doçura, intenso e infeliz, como se verifica na passagem

\footnotetext{
${ }^{20}$ Apud Lapa, 1955, p. 13-14.

${ }^{21}$ Cf. Rougemont, 1988, p. 63.
} 
do romance de Tristão e Isolda: "[...] o caminho é sem retorno, a força do amor já vos impele, e nunca mais tereis alegria sem dor". ${ }^{22}$ as CSM, por sua vez, o casamento torna-se exclusivamente motivo de felicidade, pois o amor não se encontra no sofrimento ou no adultério, mas sim nos laços perenes, estabelecidos entre os amantes.

Tragédias de amor eram comuns nos romances corteses: em Tristão e Isolda, por exemplo, depois que Tristão cai na armadilha da farinha espalhada entre o seu leito e o de Isolda, preparada pelo anão Frocino - cúmplice dos vassalos do rei Marcos, que procuram surpreender os amantes e assim denunciá-los —, os barões e o monarca irrompem no dormitório e veem manchas de sangue do ferimento de Tristão. A prova do adultério é evidente e, se não fosse a fuga de Tristão junto a Isolda, o herói seria condenado à morte e a dama entregue a um bando de leprosos. Esses elementos do amor cortês opõem-se completamente à poesia religiosa, entretanto é inegável que ambos se influenciaram, como se pode perceber nas CSM.

Para melhor explicar o que foi exposto, elaboramos abaixo um quadro das oito cantigas selecionadas, acompanhadas da temática dos romances corteses evocadas nas CSM. O objetivo do quadro é promover um maior entendimento da análise proposta, além de apresentar a ambientação das cantigas e demonstrar a amplitude das fontes dessas narrativas e os locais onde se operavam os milagres:

\begin{tabular}{|c|c|c|c|}
\hline Cantigas & Relato & Cenário & $\begin{array}{l}\text { Tópicos do amor cortês e } \\
\text { do código da cavalaria. }\end{array}$ \\
\hline 16 & $\begin{array}{l}\text { A beleza da donzela é superada pela } \\
\text { graça da Virgem. }\end{array}$ & $\begin{array}{l}\text { Ermida, } \\
\text { França. }\end{array}$ & $\begin{array}{c}\text { Virtuosidade, perda da } \\
\text { razão, } \\
\text { dame sans merci. }\end{array}$ \\
\hline 51 & $\begin{array}{l}\text { Um nobre francês sitia um castelo } \\
\text { com a intenção de conquistá-lo, } \\
\text { porém a Imagem da Virgem protege } \\
\text { um guarda. }\end{array}$ & $\begin{array}{l}\text { Orleans, } \\
\text { França. }\end{array}$ & $\begin{array}{c}\text { Proteger os cristãos e a } \\
\text { Igreja. }\end{array}$ \\
\hline 63 & A Virgem salva o cavaleiro da desonra. & $\begin{array}{l}\text { San Esteban } \\
\text { de Gormaz, } \\
\text { Espanha. }\end{array}$ & $\begin{array}{c}\text { Servir e honrar a dama, } \\
\text { valor, } \\
\text { prez, herói bom de armas. }\end{array}$ \\
\hline 121 & $\begin{array}{l}\text { O cavaleiro fazia uma guirlanda } \\
\text { de rosas em homenagem à Virgem. }\end{array}$ & $\begin{array}{l}\text { Provença, } \\
\text { França. }\end{array}$ & Fidelidade, fé. \\
\hline 155 & $\begin{array}{l}\text { Um cavaleiro busca perdão e um } \\
\text { monge lhe dá a penitência de encher } \\
\text { um tonel de água, que, no entanto, } \\
\text { permanece vazio. Após dois anos, com } \\
\text { duas lágrimas o enche. }\end{array}$ & $\begin{array}{l}\text { Alexandria, } \\
\text { Egito. }\end{array}$ & $\begin{array}{l}\text { Arrependimento, } \\
\text { vida desregrada. }\end{array}$ \\
\hline
\end{tabular}

${ }^{22}$ Cf. Bédier, 1994, p. 32. 


\begin{tabular}{|c|c|c|c|}
\hline 195 & $\begin{array}{c}\text { Santa Maria honrou um cavaleiro } \\
\text { que morreu no torneio, porque ele } \\
\text { resistiu à tentação. }\end{array}$ & $\begin{array}{c}\text { Abadia em } \\
\text { Toulouse, } \\
\text { França. }\end{array}$ & $\begin{array}{c}\text { Herói bom de armas, valor, } \\
\text { lascívia, castidade, proteção } \\
\text { dos cristãos e da Igreja. }\end{array}$ \\
\hline $\mathbf{2 3 3}$ & $\begin{array}{c}\text { Um exército celestial guarda um } \\
\text { cavaleiro fiel a Maria de seus } \\
\text { inimigos. }\end{array}$ & $\begin{array}{c}\text { S a n t o } \\
\text { Do mingo } \\
\text { de Silos, } \\
\text { Espanha. }\end{array}$ & Fidelidade. \\
\hline 292 & $\begin{array}{c}\text { Quando o rei Fernando III morreu, } \\
\text { o escultor do túmulo teve um sonho } \\
\text { com o monarca. O rei pedia que } \\
\text { construíssem sua estátua ajoelhada } \\
\text { perante a Virgem. }\end{array}$ & $\begin{array}{c}\text { S e vilha, } \\
\text { Espanha. }\end{array}$ & $\begin{array}{c}\text { Fidelidade, fé, herói } \\
\text { bom de armas, ritual de } \\
\text { adubamento. }\end{array}$ \\
\hline
\end{tabular}

Os cavaleiros dos romances corteses têm em comum a observância dos preceitos do código da cavalaria e o vínculo com os valores do amor cortês, no que tange aos prazeres da carne. O adultério era uma constante nessas narrativas, os cavaleiros traíam os seus respectivos senhores, mas ainda assim eram excelentes guerreiros e valorosos de espírito, conforme ditavam os manuais de ética da cavalaria. Um notório exemplo dessa duplicidade de comportamento encontra-se nos personagens Tristão e Lancelote, presentes nos respectivos romances Tristão e Isolda e Le Chevalier de la Charrete: ambos cometem os pecados da luxúria e do adultério, dois dos maiores segundo a ótica cristã da época. No entanto, eles respeitam os fundamentos da ordem cavaleiresca, além de conseguirem a remissão de seus pecados, através do arrependimento. Lancelote, em sua infância, gostava de caçar sozinho em uma floresta; certo dia, ele avista um senhor de idade que lamenta o insucesso na caça e o fato de não poder casar uma de suas filhas, pelo fato de não possuir montaria. Lancelote, consternado, resolve oferecer-lhe sua própria montaria de caça. ${ }^{23}$

Essa atitude exemplar de Lancelote, nos moldes do código da cavalaria, é ratificada na seguinte passagem da sexta parte do Libro de la Orden de Caballeria: Mas como ser cruel no se conciba con el oficio de caballería, por lo mismo es preciso que el caballero tenga la virtud de la caridad. ${ }^{24}$ Entre as CSM, há aquelas que narram histórias sobre cavaleiros cujos comportamentos se assemelham aos desses guerreiros emblemáticos da literatura medieval, como, por exemplo, o cavaleiro da cantiga 155, que, embora tendo sido durante toda a vida um facínora, obtém absolvição dos seus pecados depois da busca sincera de arrependimento.

Nos romances corteses e nos tratados de conduta da cavalaria, assim como nas Cantigas de Santa Maria, é notória a condição para entrar para

\footnotetext{
${ }^{23}$ Cf. Lancelot du Lac, 1991, p. 148

${ }^{24}$ Cf. Ramon Llull, 1948, p. 134.
} 
o serviço da cavalaria de Deus. Além das virtudes como ser hábil com as armas e mostrar-se valente e generoso, o cavaleiro deveria ainda praticar a fé, bem servir à Virgem e, acima de tudo, ser casto.

\section{A Virgem Maria honra o cavaleiro exemplar e virtuoso}

No século XII, a cavalaria já se tornara um corpo bem delimitado na sociedade do Ocidente medieval, e, nessa época, a França prosperou pouco a pouco, uma vez que as invasões bárbaras cessaram e os cavaleiros evitaram desgastes econômicos e sociais com suas guerras pessoais. Além disso, havia indícios de uma forte ascensão urbana, os castelos não eram mais simples fortificações isoladas, mas verdadeiras aglomerações cercadas por fossos e compostas de ruas onde viviam as famílias dos cavaleiros. Nesse contexto, o cavaleiro, vivendo com mais freqüência no castelo onde a música e a poesia tiveram um grande desenvolvimento, passou a valorizar os bons costumes, no molde dos trovadores provençais: a cortesia. Além do mais, sob a influência da Igreja, na época de Gregório Magno (séc. VII), a cavalaria passou a receber toda uma codificação ética, que serviu para direcionar a violência dessa classe feudal para um sentido utilitário, criando, para tal intento, um ritual conhecido como adubamento. Tratava-se precisamente de abençoar as armas de um neófito cavaleiro no momento de sua investidura na ordem; dessa forma, o cavaleiro passou a trilhar o caminho da militia dei.

Ramon Llull, em sua obra Libro de la Orden de Caballeria, dedicou um capítulo a pormenorizar o ritual de entrega de armas e a ensinar o aspirante a comportar-se corrretamente durante o processo. $\mathrm{O}$ primeiro procedimento, antes de o novel entrar para a ordem da cavalaria, era a obrigação de confessar os pecados, para em seguida receber a santa hóstia: La noche anterior al día en que debe ser hecho caballero, debe acudir a la iglesia para rogar a Dios. ${ }^{25}$ Ramon Llull registrou um conjunto de boas condutas do cavaleiro ideal e generoso, sendo uma das principais a defesa da Igreja e seus fiéis. "El ofício de caballero es mantener la santa fé católica por la cual creemos que Dios Padre envió su Hijo a tomar carne en la gloriosa virgen nuestra Señora gloriosa Santa Maria. [...]". ${ }^{26}$ Assim sendo, em teoria, após a investidura, o cavaleiro tornava-se um servo de Deus, defensor da Cristandade. Na cantiga 292, há uma passagem a respeito desse ritual, a qual narra a visão que teve mestre Jorge, o construtor da bela obra que é o túmulo dos pais de Afonso X (o

\footnotetext{
${ }^{25}$ Cf. Ramon Llull, 1948, p. 126.

${ }^{26}$ Cf. Ramon Llull, 1948, p. 112.
} 
Rei Fernando III e sua esposa Beatriz da Suábia) e do anel que seria posto no dedo da imagem de Fernando III: "Mas ponham-me de joelhos e que lhe ofertem o anel, pois dela obtive o reinado e a ela estou unido, pois na Igreja de Burgos fui seu cavaleiro novel". ${ }^{27}$ A cantiga revela não apenas uma cena de um ritual de entrega de armas, mas também a atitude típica de um cavaleiro diante de sua dama: a estátua de Fernando III, posicionado de joelhos diante da Virgem, ${ }^{28}$ evidencia a intenção de trovar à Virgem e a possível finalidade de atribuir ao rei cavaleiro um vínculo espiritual com o Cristianismo. A figura do cavaleiro espiritual está presente nas CSM, em relatos sobre guerreiros celestiais surgindo em auxílio dos cristãos, ou simbolizando a espiritualidade atribuída à cavalaria. $\mathrm{Na} C S M$ de número 233, temos a narrativa de um bom cavaleiro perseguido por inimigos que almejavam matá-lo quando saísse do Mosteiro de Santo Domingo de Silos, em Burgos. Após fugir a cavalo, ele se refugiou numa ermida em Portugal, onde estavam enterrados vários cavaleiros virtuosos, mortos pelos mouros no decorrer da Reconquista. Quando seus perseguidores o alcançaram nesta ermida, ele orou à Virgem pedindo-lhe auxílio. No mesmo instante a hoste de cavaleiros ali enterrada surgiu em sua defesa. Quando seus inimigos perceberam que estes guerreiros eram dos céus, pediram perdão a Deus e ao cavaleiro. Nesta cantiga, foi possível perceber o tratamento dado aos cavaleiros que seguiam os preceitos da cortesia e da cristandade: tornaram-se membros da guarda celestial, vivendo no Paraíso. ${ }^{29}$

Além das premissas básicas do comportamento da cavalaria, que salvaram o cavaleiro em apuros, há a virtude da fé, esse valor sendo invocado em muitas cantigas, como o cavaleiro da cantiga 44, que obteve o seu falcão de volta, depois de oferecer uma vela à Virgem e orar cheio de confiança. No refrão dessa cantiga já temos o conselho a respeito da fé: "Quen fiar na Madre do Salvador non perderá ren de quanto seu for". ${ }^{30}$ Foi justamente essa virtude da fé que devolveu a saúde ao rei Afonso X, o que pode ser observado nas cantigas 209, 235, 279. A maior demonstração da fé do denominado "rei sábio" encontra-se na cantiga 209, pois bastou colocar

\footnotetext{
${ }^{27}$ Mas ponan-mi en gollos, e que lle den o anel, ca dela tiv' eu o reyno e de seu Fillo mui bel, e sõo seu quitamente, pois fui cavaleir novel na ssa eigreja de Burgos do mõesteiro reyal (Mettmann, 1969, p. 104 - vol. 2, trad. nossa).

${ }^{28}$ A iluminura da cantiga 10 mostra Afonso X na mesma postura diante da Virgem, revelando a intenção de servir a Santa Maria.

${ }^{29}$ Cf. Mettmann, 1969, p. 331-332 (vol. 2).

${ }^{30}$ Cf. Mettmann, 1969, p. 332 (vol. 2).
} 
sobre o seu corpo o livro das CSM para ficar curado do mal que o afligia. ${ }^{31}$

A figura do cavaleiro fiel e confiante na proteção divina está presente em várias cantigas, como ocorre também na de número 121, que narra a história de um cavaleiro que honrava a Virgem Maria todos os dias com uma guirlanda de rosas. O cavaleiro substituía cada um das flores que porventura faltassem por uma prece. Assim ele vivia, até que um dia, totalmente desarmado, cruzou o caminho com um grupo de cavaleiros inimigos e bem armados. Os cavaleiros, aproveitando-se da situação, tentaram matá-lo, mas quando tiveram uma visão da Virgem junto ao seu alvo, um deles bradou de espanto: "Partamos logo daqui, pois não agrada a Deus que matemos esse homem, já que é um dos seus servos". ${ }^{32}$ Além de exaltar o socorro oportuno que evitou o derramamento de sangue entre cristãos, a cantiga ilustra de forma moralizante que a fé pode ser uma arma muito mais poderosa do que várias espadas. A mensagem ficou evidente: não só a fé é a mais forte das proteções, mas a Virgem não desampara aquele que nela confia, enviando até mesmo a guarda de cavaleiros celestiais. Todo cavaleiro pode tornar-se parte da "militia dei", como apregoa a visão dos cavaleiros na cantiga 233 ou mesmo o testemunho de São Jorge, que em vida fora um cavaleiro. ${ }^{33} \mathrm{Na}$ Demanda do Santo Graal, mais precisamente na passagem em que Galaaz realiza a vigília das armas para se tornar um cavaleiro, ${ }^{34}$ pode-se verificar a mesma importância religiosa atribuída ao cavaleiro, no momento da sua entrega de armas. O piedoso, místico e puro Galaaz encarna a cavalaria celestial, cuja imagem a Igreja tenta impor à cavalaria terrena. ${ }^{35}$

O monge Ramon Llull descreve a diferença entre os cavaleiros mundanos e os celestiais, conferindo a esses últimos a luta contra os homens orgulhosos. Nessa parte de sua obra, o autor queixa-se a Deus de alguns cavaleiros terem tomado um rumo contrário ao ofício da cavalaria, porque com as suas armas matam os cristãos justos. Ao falar do comportamento dos cavaleiros do céu, Ramon Llull evoca sua conduta benevolente para com os cristãos, requisito para ser um cavaleiro de Cristo: "[...] los caballeros que se combaten entre si se deshonran. Mas en la batalla de los caballeros celestiales no sucede así; porque combaten con lealtad contra los orgullosos". No

\footnotetext{
${ }^{31}$ Cf. Mettmann, 1969, p. 275 (vol. 2).

${ }^{32}$ Tornemo-nos daqui logo, pois esto non praz a Deus que est' ome nos matemos, ca x'éste dos servos seus (Mettmann, 1969, p. 58-29 - vol. 2, trad. nossa).

${ }^{33}$ Cf. Jacopo de Varazze, 2003, p. 365-370.

${ }^{34}$ Cf. Magne, 1944, p. 40.

${ }^{35}$ Cf. Le Goff, 1967, p. 195-199.
} 
corpus das CSM, a cantiga 15 trata do cavaleiro legendário, São Mercúrio, que fora convocado pela Virgem para lutar contra Juliano, o Apóstata. O cavaleiro branco monta em seu cavalo e lança-se contra Juliano, ferindo-o mortalmente no abdômen. A mesma cavalaria celestial ressurge na cantiga 165 para proteger uma cidade dos mouros, porém em grande número: "O mouro respondeu com a seguinte história: "Senhor, tudo o que eu disse é verdade, porém veja que todos esses cavaleiros são do céu, pois são mais brancos do que a neve e o cristal". ${ }^{36}$

As vestimentas brancas desses cavaleiros das cantigas 15 e 165 são característica marcante na literatura medieval e indicam a procedência espiritual dessa cavalaria. Um fato interessante que se percebe nas iluminuras da cantiga 63 é justamente a cor branca da vestimenta do cavaleiro, tanto do substituído como do substituto espiritual, o qual se relaciona com o pacto espiritual estabelecido no momento do ritual de adubamento, o que coaduna com a hipótese de se tratar de um desses cavaleiros celestiais, que lutou no lugar do cavaleiro da cantiga 63, revelando possivelmente a sua identidade. Na cantiga citada, um cavaleiro encontra-se dividido entre o dever que vota ao seu senhor e a devoção à Virgem ao ser convocado para auxiliar no combate contra o rei Almanzor no mesmo dia em que assistia a missa em nome da Virgem. O cavaleiro, então, optou por honrar a Virgem em detrimento da convocação do seu senhor e consequentemente do seu renome; no entanto, Santa Maria não permitiu que o seu cavaleiro caísse em desonra, substituindo-o por um cavaleiro celestial. O guerreiro espiritual realizou façanhas bélicas grandiosas a ponto de deixar perplexo Don Garcia, o que rendeu ao cavaleiro substituído honrarias e agradecimentos, devido aos seus bravos feitos de armas. Auxiliar o seu senhor era um dos mais importantes deveres do cavaleiro estabelecidos em seu adubamento: "Es oficio de caballero mantener y defender a su señor terrena". Afonso X lidou, durante seu reinado, com o que ele chamou de "cavaleiros covardes", assunto que será tratado adiante.

Dominique Barthélemy afirma que a fusão da cavalaria com a nobreza e o desenvolvimento dos romances corteses exaltavam os ânimos dos jovens cavaleiros, como aconteceu com D. Nuno Álvares Pereira, que almejou imitar Galaaz e sua perfeição espiritual. A cavalaria criou um sentimento de pertencimento às normas espirituais da Igreja e ao intricado código cortês, que

\footnotetext{
${ }^{36}$ O mouro, con mui gran medo, lle respos esta razon: "Sennor, quanto vos eu dixe verdad' este e al non; mas tod' estes cavaleiros, vedes que dos Ceos son, ca chus brancos son e craros que é neve nen cristal” (Mettmann, 1969, p. 168 - vol. 2, trad. nossa).

${ }^{37}$ Cf. Ramon Llull, 1948, p. 114.
} 
a transformou numa instituição dotada de organização e de código de moral próprios, imbuída de um tom espiritual e ascético, como citado na obra de Ramon Llull e inclusive no tratado jurídico de Afonso X, a partida II de Las Siete Partidas. O cavaleiro surgiu, portanto, na literatura medieval, figurado em seu lado moral, imbuído simultaneamente do ideal cristão e cortês.

Nas cantigas 233 e 121 podemos observar outro aspecto importante do imaginário medieval, conhecido como trégua de paz, para explicar como se desenvolveu a submissão dos cavaleiros à Igreja. Em ambas as cantigas, os envolvidos em querelas são cavaleiros, mas a Virgem havia coibido derramamento de sangue entre cristãos. Essa trégua consistiu em coibir todo ato de guerra e violência de cristão contra cristão. Nos escritos de Guifredo de Narbona, quando foi realizada a segunda publicação da trégua de Deus, em 1054, há a seguinte cláusula: "Que nenhum cristão mate um outro cristão; pois aquele que mata um cristão derrama o sangue do Cristo".

$\mathrm{Na}$ cantiga 19, a Virgem demonstrou total desagrado quando dois cavaleiros executaram um homem diante do altar de uma Igreja, e o ato foi prontamente punido por ela: "Esta é como Santa Maria fillou vingança dos tres cavaleiros que mataron seu emigo ant' o seu altar". Um cavaleiro deveria usar suas armas apenas contra os inimigos da Igreja, entretanto Ramon Llull ratificou que nem todos os cavaleiros seguiam esse aforismo da ordem: "Mas paréceme, Señor, que los caballeros han tomado otro rumbo contrario al oficio, porque con las armas con que debieran destruir a los malos hombres, vemos que matan a hombres justos [...]". ${ }^{39}$ Não somente os tratados sobre a conduta cavaleiresca, mas também as obras jurídicas tiveram um importante papel na divulgação do ideal cristão e cortês da cavalaria. No tratado jurídico Las Siete Partidas, desenvolvido por Afonso X, o virtuoso cavaleiro destaca-se através de qualidades essenciais como a mesura nos atos, honra, valor e generosidade. "Commo los cavalleros deven aver en sy quatro virtudes prinçipales: cordura, e fortaleza, e mesura e justiçia". (Partida II, XXI, 4); além do dever da prática dos bons costumes: "E esto que de una parte sean fuertes e bravos, e de outra mansos e omildosos"; (Partida II, XXI, 7). A cortesia incluía-se no mesmo rol de virtudes a serem observadas pela cavalaria: "E los que desto se usaren de las palabras buenas, llamaron los buenos e otrossy llamaronlos corteses [...]". ${ }^{40}$

Parece haver um consenso sobre a abordagem do virtuosismo da cavalaria nas CSM que coaduna com as regras de boa conduta registradas na partida II acima referidas: "Este namorado foi cavaleiro de grandes

\footnotetext{
${ }^{38}$ Cf. Barthélemy, 2010, p. 319.

${ }^{39}$ Cf. Ramon Llull, 1948, p. 148.

${ }^{40}$ Cf. Afonso X, 1807, p. 197-219.
} 
feitos de armas, além de formoso, belo e franco; [...]" CSM 16; "Este cavaleiro, como ouvi, era tão valente que niguém possuía maior habilidade no manejo das armas [...]" CSM $63{ }^{42}$ outras cantigas possuem também o mesmo tom elogioso. Na introdução do título XXI da segunda partida, é enfatizada a honra da cavalaria, estando ela acima de todas as outras classes sociais de guerreiros. ${ }^{43}$

Percebem-se, também, nas cantigas, as atitudes que Afonso X reprovava na cavalaria, evidenciando qual era a conduta correta a ser seguida; como na cantiga 155, que narra a história de um cavaleiro idoso arrependido por ter vivido como um ladrão malfeitor. Em nenhuma estrofe da cantiga há uma descrição virtuosa do cavaleiro, a não ser no momento do seu arrependimento. $\mathrm{Na}$ busca de perdão com um santo monge, é recomendado ao cavaleiro fazer uma peregrinação, mas ele se recusa a realizá-la, e o monge então lhe ordena o jejum, mas ele também se opôs a isso, assim como a dar esmola. Por fim, o eremita pediu-lhe para ir encher uma jarra de água; se conseguisse realizar tal tarefa, iria ganhar o perdão. O cavaleiro tentou de todas as formas encher a jarra, porém a água era drenada para fora do tonel. Por dois anos ele tentou e nada conseguiu. Concluindo que Deus nunca o perdoaria, rogou à Virgem, em prantos, pela sua salvação. Duas lágrimas do seu arrependimento pousaram no tonel e encheram-no por completo. ${ }^{44}$ Fica claro o quanto era penoso alcançar o perdão dos pecados e, no caso da cavalaria, há uma sanção pelo fato de o cavaleiro agir contrariamente às virtudes da ordem.

Entre as falhas da cavalaria, a mais rechaçada por Afonso $\mathrm{X}$ era a traição em relação aos deveres de auxílio ao senhor feudal: "El malvado caballero que no ayuda a su señor terrenal contra otro príncipe, es caballero sin oficio $[\ldots] "{ }^{45}$ Há, no conjunto das obras afonsinas, um grupo de cantigas de escárnio dirigidas a cavaleiros que traíram o código da cavalaria, no que tange a atender ao chamado do seu senhor. Trata-se das cantigas que têm como motivo o comportamento dos cavaleiros nas campanhas que Afonso $\mathrm{X}$ levou a cabo na Andaluzia. O monarca atacou de forma feroz e mordaz a covardia desses cavaleiros, que traíram o seu dever de vassalos do rei,

\footnotetext{
${ }^{41}$ Este namorado foi cavaleiro de gran prez d'armas, e mui fremos' e apost' e muy fran [...] (Mettmann, 1969, p. 49-51 - vol. 1, trad. nossa).

${ }^{42}$ Este cavaleiro, per quant' aprendi, franqu' e ardid'era, que bes ali u ele morava nen redor dessi d'armas non podian outro tal saber (Mettmann, 1969, p. 178-181 - vol. 1, trad. nossa).

${ }^{43}$ Cf. Afonso X, 1807, p. 197-219.

${ }^{44}$ Cf. Mettmann, 1969, p. 146-148 (vol. 2, trad. nossa).

${ }^{45}$ Cf. Ramon Llull, 1948, p. 115.
} 
na campanha contra os mouros de Múrcia e Granada. "Múrcia e Granada vi coitefes orpelados estar mui mal espantados, e genetes trosquiados [...]". ${ }^{46} \mathrm{Nessa}$ cantiga de escárnio é nítido o tom irônico e indignado de Afonso X diante da traição dos cavaleiros. No título XXI, lai nove da partida II, ${ }^{47}$ é descrita a prática imprescindível da lealdade, já que nesse valor se encerram todas as virtudes, e Afonso X asseverou que todos os cavaleiros deveriam guardálo, pois uma das razões expostas seria a defesa da terra, e quem não fosse leal não poderia ser um bom protetor do reino e, portanto, não caberia ser intitulado cavaleiro. Mesmo que na prática poucos cavaleiros seguissem as normas, havia um consenso entre as obras poéticas e as de cunho jurídico: a condenação da traição do cavaleiro a seu rei e principalmente ao código da cavalaria.

A honra e a glória são de suma importância para o cavaleiro, e a humilhação, por faltar à batalha, beirava o insuportável. Jean Flori faz referência ao comportamento excessivo de Rolando, o qual recusa, com aversão, tudo o que poderia estar relacionado à covardia, defeito irredimível, que os cavaleiros evitavam a todo custo, para que os jograis não pudessem "cantar uma canção ruim" a seu respeito.

\section{Feitos de combate e torneios: virtudes do bom cavaleiro}

A partir das considerações acima citadas entende-se melhor o alívio do cavaleiro da cantiga 63, ao perceber que sua armadura estava com marcas de batalha e seu corpo marcado de feridas. Da mesma forma, em toda a literatura que trata desse assunto, inclusive nos romances corteses, podemos encontrar exemplos do cavaleiro de brio, nos moldes do código de conduta moral. O maior exemplo é Lancelote, do romance Le Chevalier de la Charrete, que realiza proezas para libertar a rainha Guinevere, um perfeito cavaleiro, bravo no combate e amante cortês. Depois de várias provas de brio guerreiro, Lancelote encontra Guinevere, que o trata com muita indiferença e rudeza, no momento em que revela hesitação ao entrar na charrete, símbolo de desonra. Apenas mais tarde, por considerar o valor do cavaleiro, Guinevere concedeu-lhe a recompensa por tanta fidelidade e pelos serviços tão árduos, na forma de um encontro noturno, culminando no adultério. $\mathrm{O}$ amor de Lancelote por Guinevere alcançava as fronteiras da adoração religiosa; Lancelote tinha gestos, ao reverenciar sua amada, semelhantes à postura de um fiel diante de Santa Maria. O serviço do

\footnotetext{
${ }^{46}$ Cf. Lopes, 1994, p. 35-88.

${ }^{47}$ Cf. Afonso X, 1807, p. 197-219.
} 
amor é mais poderoso que a própria honra e por causa dela o cavaleiro pôde se expor à infâmia. No entanto, nas CSM a dama celestial não exigia a sua humilhação; ao contrário, o cavaleiro tinha a sua honra protegida. Quanto ao adultério cometido por Lancelote e Guinevere, de acordo com o imaginário medieval, ele está intimamente relacionado com a tentação da carne, sendo contrário à virtude da castidade.

Dominique Barthélemy afirma que, por mais diferentes que sejam os ideais propostos à cavalaria pela Igreja e pela literatura aristocrática, eles convergem em muitos pontos, em particular, naqueles que tendem a elaborar um código de conduta menos violenta, poupando vidas humanas nos meios guerreiros aristocráticos e nas populações cristãs e prescrevendo, além disso, o respeito às damas. Essa constatação, de acordo com Jean Flori, não é nada surpreendente, pois muitos poetas e romancistas eram eles próprios clérigos ou viveram em mosteiros, como o renomado Chrétien de Troyes.

O torneio é outro fator da cavalaria que podemos encontrar tanto na literatura quanto nos tratados sobre a conduta cavaleiresca. Esses combates não eram tão perigosos quanto as guerras verdadeiras e o objetivo principal consistia mais em ampliar a glória e o prestígio do que em matar o adversário, porém os acidentes eram frequentes, como relatado na cantiga 195, em que o cavaleiro encontra a morte no torneio. Ramon Llull, em sua obra, no capítulo que trata do ofício do cavaleiro, cita: "Es oficio de caballero, correr en caballo bien guarnecido, jugar la lanza en las lizas, andar con armas, torneos $[\ldots] "{ }^{48}$ Esse tópos ocorre novamente na CSM 63, acima citada. Assim sendo, saber manejar as armas está relacionado com um dos requisitos para tornar-se um cavaleiro ideal na obra afonsina, o que de resto se verifica com a literatura cavaleiresca medieval. Entretanto, no corpus das cantigas, apenas a cantiga 195, acima referida, cita o evento do torneio e ainda assim o foco é o milagre da Virgem, que recompensa o cavaleiro dando-lhe um digno sepultamento cristão, por ter respeitado o dia santo e a vontade da donzela. ${ }^{49}$ Como a Igreja condenava os torneios, possivelmente tal fato evidencia o motivo de sua escassa referência na literatura religiosa. O Libro de la Orden de Caballeria, de caráter cristão, possui apenas duas referências aos torneios, no prólogo e na segunda parte da obra.

\footnotetext{
48 "É incumbência de um cavaleiro, cavalgar em cavalo bem guarnecido, jogar a lança nas liças, andar com armas, torneios [...]. (Ramon Llull, 1948, p. 114-115, tradução nossa).

${ }^{49}$ Cf. Mettmann, 1969, p. 239-245
} 
Nas palavras de Dominique Barthélemy, uma das mais importantes obrigações de um cavaleiro era proteger a Igreja e os cristãos. Entre as motivações para essa regra, além da proteção contra os perigos - como ladrões e assassinos - , estava a relação inicial da Igreja com essa classe guerreira. No início do séculoX, havia um clima de desconfiança por parte da Igreja, que muitas vezes confundia os cavaleiros com ladrões, devido ao seu comportamento ainda não moldado pela corte e pela Igreja. Essa desconfiança fez nascer o movimento da Paz de Deus, em torno do ano 1000, destinado a submetê-los às diretivas da Igreja. Os cavaleiros receberam a missão de proteger a cristandade: "Es oficio del caballero defender la santa Fe católica, por la cual Dios padre envió a su Hijo a tomar carne en la Virgen gloriosa $y$ para honrar a la $\mathrm{Fe}[. .$.$] ]". A cantiga 51$ trata justamente da observância desse preceito da cavalaria. O relato apresenta um dos condes de Peiteus, ${ }^{50}$ cuja identidade não nos é revelada, contudo o real interesse para esse trabalho não seria determinar a sua identidade, mas sim demonstrar os motivos que levaram ao arrependimento desse conde no final da cantiga. Achamos interessante realizar uma tradução livre desse relato, devido à dificuldade de resumir essa cantiga, que possui uma narrativa mais complexa, em razão do maior número de personagens:

Quero contar-lhes uma demonstração que fez Santa Maria, na terra de Orleans, ao Conde de Peiteus, que cercara um castelo. Contudo, os moradores do castelo colocaram sobre a porta a imagem de Maria, para protegê-los. As pessoas do castelo, entre lágrimas, rezaram a Maria. Então, um dos homens do conde veio com uma besta, e disse ao porteiro que se encontrava atrás da Imagem buscando proteção, para abrir os portões. O porteiro disse que não abriria; como resposta o Besteiro atirou sua flecha, que ia atingi-lo se o joelho da imagem não tivesse interceptado a flecha. Todos os presentes viram essa maravilha; então o conde desceu do seu cavalo, e como um romeiro entrou na cidade, e de joelhos diante da imagem orou à majestade reconhecendo, enfim, a sua maldade.

O reconhecimento por parte do conde de sua própria maldade no final dessa cantiga estaria diretamente relacionado ao preceito da ordem da cavalaria anteriormente mencionado: "proteção aos cristãos". O conde percebeu, graças ao milagre da Virgem, o erro cometido, já que os habitantes daquele castelo eram todos cristãos e estavam indefesos perante as forças dele, o que contrariou mais um ditame da ordem da cavalaria exposto em Ramon Llull: “[...] Si destruir

\footnotetext{
${ }^{50}$ Atual cidade de Poitiers, na França.
} 
villas y ciudades $y$ devastar arboledas $y$ plantaciones, $y$ robar a los viandantes, fuese oficio de caballero, el obrar castillos serían desordenamiento de caballería". ${ }^{51}$

Como observado a partir da análise das cantigas acima citadas, assim como em outras do corpus afonsino, o abandono do pecado só acontece depois da intercessão da Virgem. Apresentamos as motivações que levaram Afonso $\mathrm{X}$ a registrar na compilação das CSM a presença da cavalaria, principalmente dos nobres enquanto cavaleiros. As motivações são várias e com toda certeza não caberia neste artigo o estudo de todas, mas observamos, até aqui, uma intenção moralizante e educadora da ordem da cavalaria. Nos preceitos da Paz de Deus e nos juramentos realizados durante o ritual de adubamento, o cavaleiro deveria ser, como já visto, hábil com as armas, brioso, bondoso, protetor da cristandade, fiel à Igreja e à Virgem, sem se esquecer de se portar como detentor de bela compleição física e de caráter aguerrido, o que lhe rendia aventuras amorosas, como observado nos romances corteses.

\section{Referências}

AFONSO X. Las siete Partidas del Rey Alfonso el Sabio: Tomo II. Madrid: Imprensa Real, 1807.

AFONSO X. Cantigas de Santa María: codice Rico de El Escorial, ms. escurialense T.I.1. Introducción, versión castellana y comentarios de José Filgueira Valverde. Madrid: Editorial Castalia, 1985.

ANÔNIMO. Lancelot du Lac: roman français $d u$ XIII ${ }^{\circ}$ siècle - vol I. $2^{\text {a }}$ edition. Présenté, trad. et annoté par François Mosès. Paris: Lettres Gothiques, 1991.

BARTHÉLEMY, D. A cavalaria: da Germânia antiga à França do século XII. Trad. Néri de Barros Almeida e Carolina Gual da Silva. Campinas: Editora da Unicamp, 2010. BÉDIER, J. O romance de Tristão e Isolda. Trad. Luis Claudio de Castro e Costa. São Paulo: Martins Fontes, 1994.

CHRÉTIEN DE TROYES. Oeuvres complètes. Paris: Éditions Gallimard, 1994.

DISALVO, S. A. La Cultura monástica en las Cantigas de Santa María de Alfonso X: pervivencia, adopción, reelaboración. Tese de doutorado apresentada para obtenção do grau de doutor em Letras. La Plata: Universidad Nacional de La Plata/ Facultad de Humanidades y Ciencias de la Educación, 2008.

FILGUEIRA VALVERDE, J. Cantigas de Santa Maria. Madrid: Editorial Castalia, 1985. FLORI, J. A cavalaria: a origem dos nobres guerreiros da Idade Média. Trad. Eni Tenório dos Santos. São Paulo: Madras, 2005.

${ }^{51}$ Cf. Ramon Llull, 1948, p. 118. 
GUILHERME IX. Poesia. Trad. e Introd. Arnaldo Saraiva. Campinas: Editora da Unicamp, 2009.

JACOPO DE VARAZZE. Legenda Áurea: vidas de santos. Trad. e notas Hilário Franco Júnior, São Paulo: Companhia das Letras, 2003.

JARDIM, R. B. Ave Maria, ave senhora de todas as graças! Um estudo do feminino nas perspectivas das relações de gênero na Castela do século XIII. Tese de doutorado, Faculdade de Filosofia e Ciências Humanas. Porto Alegre: PUCRS, 2006.

KOËHLER, E. L'aventure chevaleresque: idéal et réalité dans le romain courtois. Paris, Gallimard, 1980.

LANCIANI, G.; TAVANI, G. (org.). Dicionário da literatura medieval galega e portuguesa. Lisboa: Editora Caminho, 1993.

LAPA, M. R. Lições de literatura portuguesa: época medieval. Coimbra: Coimbra Editora, 1955.

LEÃO, A. V. Cantigas de Santa Maria de Afonso X, o Sábio: aspectos culturais e literários. São Paulo/ Belo Horizonte: Linear B/ Veredas e Cenários, 2007.

LEÃO, A. V. Cantigas de Santa Maria (antologia, tradução e comentários). Belo Horizonte: Veredas, 2011.

LE GOFF, J.; SCHMITT, J.-C. Dicionário temático do Ocidente Medieval. Coord. da trad. Hilário Franco Júnior. Bauru: Edusc, 2006, p. 195-199.

LE GOFF, J. Culture cléricale et traditions folkloriques dans la civilisation mérovingienne. Annales: économies, sociétés, civilisations, Paris, $22^{\text {ème }}$. année, n. 4, p. 780-791, 1967.

LOPES, G. V. A sátira nos cancioneiros medievais galego-portugueses. Lisboa: Editorial Estampa, 1998.

MAGNE, A. A demanda do Santo Graal. Rio de Janeiro: Imprensa Nacional, 1944. METTMANN, W. Cantigas de Santa Maria de Afonso X, vols. I, II, III, IV. Coimbra: Universidade de Coimbra, 1969.

RAMON LLULL. Libro de caballeria, blanquerna, felix, poesías: edicion preparada y anotada por los padres Miguel Batillori y Miguel Caldentey. Madrid: Católica, 1948.

de ROUGEMONT, D. O Amor e o Ocidente. Trad. Paulo Brandi e Eyhel Brandi Cachapuz. Rio de Janeiro: Guanabara, 1988.

SOKOLOWSKI, M. Por Santa Maria! A fina flor da cavalaria nas Cantigas de Afonso X (1252-1284). Monografia em história, Faculdade de Filosofia e Ciências Humanas. Curitiba: Universidade Federal do Paraná, 2010.

ZUMTHOR, P. A letra e a voz: a literatura medieval. Trad. Amálio Pinheiro, Jerusa Ferreira. São Paulo: Cia. das Letras, 1983, p. 35-54. 